\title{
PEMBELAJARAN STUDENT TEAM ACHIEVEMENT DIVISION UNTUK MENINGKATKAN HASIL BELAJAR SISWA
}

\author{
${ }^{1}$ Juraida Hasibuan, ${ }^{2}$ Ahmad Nizar Rangkuti*, ${ }^{3}$ Latifa Annum Dalimunthe \\ nizarahmad1304@yahoo.com \\ ${ }^{1}$ SMPN 3 Padangsidimpuan \\ ${ }^{2,3}$ Fakultas Tarbiyah dan Ilmu Keguruan IAIN Padangsidimpuan
}

\begin{abstract}
The purpose of this research is to know whether there is the effect of Student Team Achievement Division (STAD) cooperative learning models on the result of learning the subject of Imitating the Obedience Angels of Allah SWT at Grade VII Students of SMP Negeri 3 Padangsidimpuan. This kind of research is quantitative research through the test to collect the data. The test form is multiple choice as many as 20 questions that have been validated. After analyzing the data the researcher found that the main score of experimental class before using Student Team Achievement Division (STAD) was 61.5 and mean score after using Student Team Achievement Division (STAD) was 83.46. By using the T-test, the researcher found that $\mathrm{t}_{\text {-table }}$ was higher than $\mathrm{t}$-count $(5.7>1.677)$ with significant level 0.05 .
\end{abstract}

\begin{abstract}
ABSTRAK
Penelitian ini bertujuan untuk mengetahui pengaruh model pembelajaran kooperatif tipe Student Team Achievement Division(STAD) terhadap hasil belajar pokok bahasan meneladani ketaatan malaikat-malaikat Allah Swt kelas VII di SMP Negeri 3 Padangsidimpuan. Penelitian ini adalah kuantitatif melalui tes sebagai pengumpulan data dimana bentuk tes berupa pilihan berganda sebanyak 20 butir soal yang sudah valid. Hasil penelitian menunjukkan bahwa ada pengaruh penggunaan metode Student Team Achievement Division terhadap hasil belajar siswa. Hal ini dapat dilihat bahwa pokok bahasan meneladani ketaatan malaikat-malaikat Allah Swt kelas VII8 di SMP Negeri 3 Padangsidimpuan yaitu nilai rata-rata kelas eksperimen dari 61.5 menjadi 83.46. Dengan menggunakan uji-t diperoleh $t_{\text {hitung }}>t_{\text {tabel }}$ yaitu 5.7> 1.677 dengan taraf signifikan 0,05 .
\end{abstract}

Kata Kunci: Pendidikan Agama Islam; Student Team Achievement Division; Hasil Belajar.

\section{PENDAHULUAN}

Pendidikan Islam adalah pendidikan yang bertujuan untuk membentuk pribadi muslim seutuhnya, mengembangkan seluruh potonsi manusia baik yang berbentuk jasmaniyah maupun ruhaniyah, menumbuhkan hubungan yang harmonis setiap pribadi manusia dengan Allah, manusia dan alam semesta. ${ }^{1}$ Selain itu tujuan pendidikan Islam terkait erat dengan tujuan penciptaan manusia sebagai khalifah Allah SWT. Seperti rincian Atiyah Al-Abrasyi mengenai

\footnotetext{
${ }^{1}$ Haidar Putra Daulay, Pendidikan Islam Di Indonesia (Medan: Perdana Publishing, 2012), hlm. 1.
} 
tujuan pendidikan Islam yaitu: ${ }^{2}$ untuk membantu pembentukan akhlak yang mulia; persiapan untuk kehidupan dunia dan akhirat; menumbuhkan ruh ilmiyah; menyiapkan peserta didik dari segi professional; dan persiapan untuk mencari rezki.

Salah satu tujuan pendidikan adalah untuk mengupanyakan peserta didik agar memiliki kemampuan dan keahlian khusus sesuai dengan bakatnya. Seperti yang difirmankan Allah dalam Q.S Hud11:61:

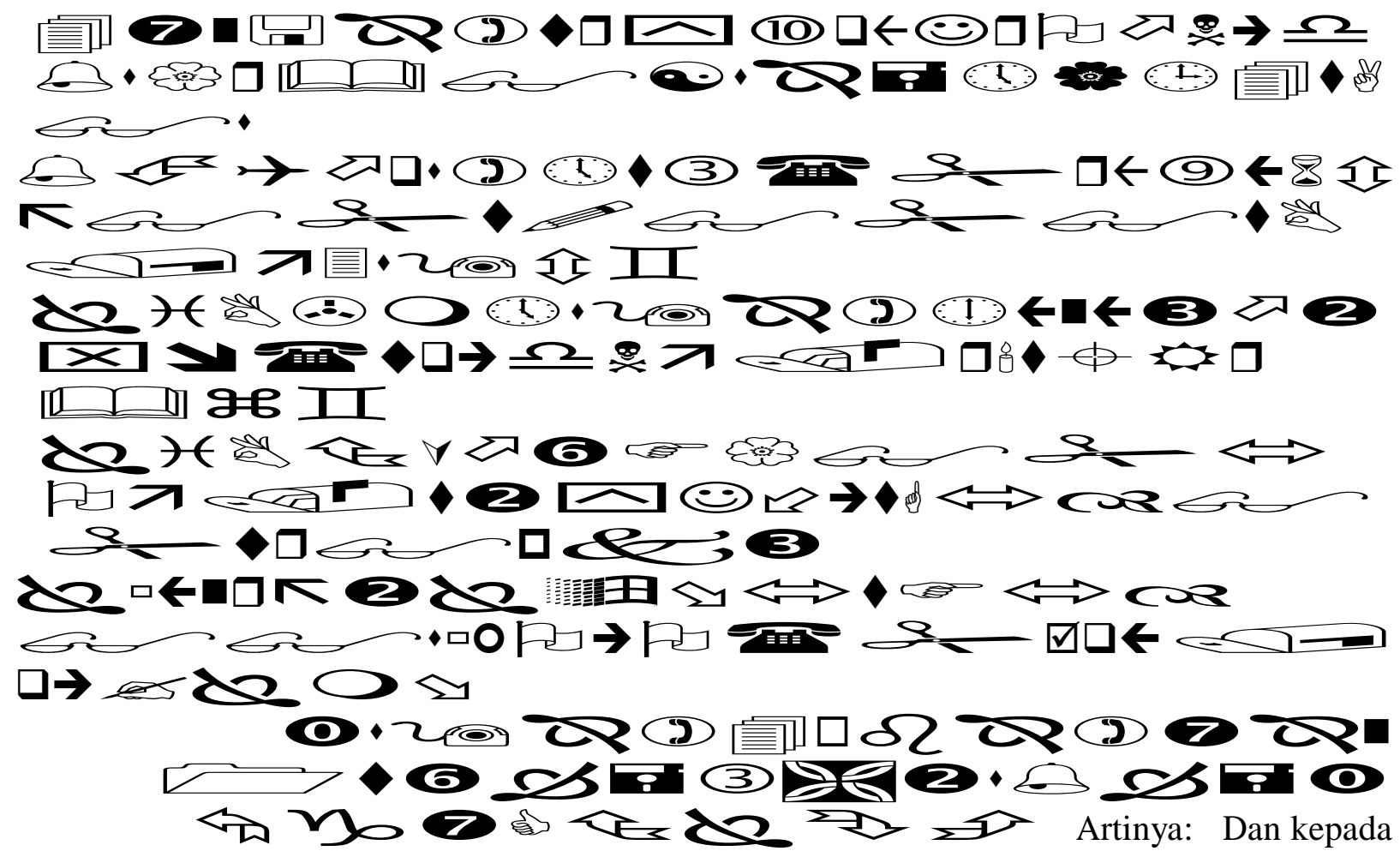

Tsamud (kami utus) saudara mereka shaleh. Shaleh berkata: "Hai kaumku, sembahlah

Allah, sekali-kali tidak ada bagimu Tuhan selain Dia. Dia telah menciptakan kamu dari bumi (tanah) dan menjadikan kamu pemakmurnya[726], karena itu mohonlah ampunan-Nya, kemudian bertobatlah kepada-Nya, Sesungguhnya Tuhanku Amat dekat (rahmat-Nya) lagi memperkenankan (doa hamba-Nya)."

Ayat di atas secara umum memberikan makna bahwa pendidik harus mampu merancang kegiatan pembelajaran dengan baik dan tepat sesuai dengan tujuan pembelajaran. Kegiatan pembelajaran lebih dipandang dari segi prosesnya, dalam pemberian makna terhadap objek dan pengalaman individu tidak dilakukan sendiri-sendiri oleh peserta didik, tetapi melalui interaksi dalam jaringan sosial yang unik yang terbentuk dalam budaya kelas maupun luar kelas. ${ }^{3}$

Mengajar bukan kegiatan memindahkan pengetahuan dari pendidik kepada peserta didik semata, namun peserta didik harus bisa belajar secara mandiri sehingga dapat membangun 
pengetahuan secara dewasa. Maka salah satu cara yang dilakukan guru dalam menyampaikan materi ajar adalah dengan menggunakan startegi pembelajaran. Srategi pembelajaran adalah suatu kegiatan yang dipilih pendidik dalam proses pembelajaran agar tujian pembelajaran dapat dicapai dengan baik. ${ }^{4}$

Dalam proses pembelajaran ada hal penting yang harus diperhatikan yaitu pendekatan pembelajaran yang berpusat pada peserta didik. Dengan demikian, efektivitas pembelajaran merujuk pada keberhasilan seluruh komponen pembelajaran yang diorganisasikan untuk

\footnotetext{
${ }^{2}$ Haidar Putra Daulay, Pendidikan Islam Di Indonesia. hlm. 3.

${ }^{3}$ Asri Budi Ningsih, Belajar dan Pembelajaran (Jakarta: PT. Rineka Cipta, 2005), hlm. 58.

${ }^{4}$ Hamruni, Strategi Pembelajaran (Yogyakarta: Insan Media, 2012), hlm. 12.
} 
mencapai tujuan pembelajaran yang telah ditentukan. Sedangkan tujuan dari kegiatan belajar sendiri, tidak akan pernah tercapai jika pemilihan dan penentuan model tidak dilakukan pengenalan atau pemahaman dengan karakteristik dari model tersebut. Jadi, seorang pendidik sebaiknya menggunakan model yang dapat menghidupkan suasana pembelajaran, sehingga bisa dijadikan alat yang efektif untuk mencapai tujuan dan hasil pembelajaran. ${ }^{5}$

Model pembelajaran kooperatif memiliki nilai lebih untung meningkatkan keaktifan peserta didik dalam proses pembelajaran. Tipe Student Team Achievement Division merupakan salah satu model pembelajaran. Model pembelajaran kooperatif tife STADmerupakan model pembelajaran kooperatif yang sederhana. Guru cukup membagi peserta didik menjadi beberapa kelompok yang heterogen. Setelah itu guru menyajikan pelajaran, kemudian peserta didik bekerja dalam tim untuk memastikan semua anggota kelompok menguasai pelajaran. Pada akhir pembelajaran, guru memberikan penghargaan kepada kelompok yang terbaik untuk memotivasi kelompok yang lain. ${ }^{6}$

Sebelumnya beberapa peneliti terdahulu menunjukkan bahwa model pembelajaran kooperatif tipe STAD sudah pernah diterapkan dalam proses pembelajaran. Penelitian tentang model pembelajaran kooperatif tipe STAD ini ada yang diterapkan pada mata pelajaran umum dan agama. Sebab kooperatif tipe Student Team Achievement Division termasuk model pembelajaran yang mengharuskan aktivitas, interaksi sesama teman kelompok untuk saling memberikan dorongan atau motivasi, saling membantu menguasai bahkan memahami materi pelajaran yang dibangikan. Oleh karena itu, peneliti ingin menguji pengaruh model pembelajaran kooperatif tipe STAD pada mata pelajaran pendidikan agama Islam, pokok bahasan meneladani ketaatan malaikat-malaikat Allah Swt, terhadap hasil belajar siswa.

Dengan menerapkan model STAD ini, diharapkan siswa memiliki pengalaman baru dalam belajar, mampu meningkatkan hasil belajar siswa sesuai yang diharapkan, karena tujuan dari pembelajaran itu adalah mencapai indikator yang telah ditetapkan, karena itu stategi dan metode perlu dugunakan agar siswa tidak merasa jenuh dalam mengikuti proses pembelajaran. hlm. 85 .

${ }^{5}$ Syaiful Bahri Djamarah dan Aswan Zain, Strategi Belajar Mengajar (Jakarta: PT. Rineka Cipta, 2006),

${ }^{6}$ Supriyadi, Syamsul Bahri, Amiruddin Kade, “Pengaruh Mode Pembelajaran Kooperatif Tipe STAD Dalam Meningkatkan Hasil Belajar Fisika Peserta Didik Kelas X SMK N 6 Palu Tahun Ah=jaran 2016/2019,” Jurnal Magistra, Volume 5, No. 2 Juli (2018), hlm. 66, Available online at http://ejournal.unmus.ac.id/index.php/magistra. 
Teori yang digunakan pada penelitian ini adalah teori belajar konstruktivisme, karena teori konstruktivesme menuntut siswa untuk membangun pengetahuan yang dimiliki siswa sehingga menemukan ide-ide yang mendorong kesadaran siswa untuk belajar. Teori belajar konstruktivisme adalah pembelajaran yang bersifat generatif, artinya tindakan yang menciptakan suatu makna dari apa yang dipelajari. Adapun konsep utama dalam teori konstruktivisme yaitu peserta didik akan aktif untuk membuat pengertian apa yang dipahami siswa tersebut.Teori belajar konstruktivisme adalah pembelajaran yang bersifat generatif, artinya tindakan yang menciptakan suatu makna dari apa yang dipelajari. Adapun konsep utama dalam teori konstruktivisme yaitu peserta didik akan aktif untuk membuat pengertian apa yang dipahami siswa tersebut.

Dari hasil wawancara yang dilakukan peneliti di SMP Negeri 3 Padangsidimpuan, bahwa pembelajaran lebih berpusat kepada guru, pembelajaran lebih sering menggunakan metode ceramah, diskusi dan Tanya jawab yang mengakibatkan pembelajaran menjadi tidak menyenangkan, kurang aktifnya siswa dalam belajar dan siswa tidak menemukan sendiri konsep dari materi sehingga berdampak pada hasil belajar siswa. Hal ini dikemukakan oleh salah satu guru agama Islam, yaitu ibu Siti Roilan. ${ }^{7}$

Berdasarkan latar belakang di atas, maka dapat diidentifikasikan masalah sebagai berikut:

1. Siswa masih kurang aktif dalam proses pembelajaran sehingga hasil belajar tidak tercapai dengan yang diharapkan.

2. Guru menyampaikan pelajaran masih monoton dengan menggunakan metode ceramah, diskusi, Tanya jawab.

Tujuan penelitian ini adalah untuk mengetahui apakah terdapat pengaruh model pembelajaran kooperatif tipe Student Team Achievent Division (STAD) terhadap hasil belajar siswa pokok bahasan meneladani ketaatan malaikat-malaiakat Allah Swt kelas VII di SMP Negeri 3 Padangsidimpuan.

\section{METODE}

Jenis penelitian yang digunakan oleh peneliti adalah jenis penelitian kuantitatif dengan menggunakan metode eksperimen. Metode eksperimen adalah metode pemberian kesempatan kepada anak didik baik perorangan atau kelompok, untuk dilatih melakukan suatu proses atau

${ }^{7}$ Siti Roilan, Guru Pendidikan Agama Islam Kelas VII Smp Negeri 3 Padangsidimpuan (Wawancara di Padangsidimpuan Oktober 2018, 10.00 WIB) 
percobaan. ${ }^{8}$ Selain itu metode eksperimen merupakan suatu metode penelitian yang digunakan untuk mencapai pengaruh perlakuan tertentu terhadap yang lain dalam kondisi yang terkendalikan. ${ }^{9}$

Penelitian ini akan melihat apakah ada pengaruh model student team achievement division terhadap hasil belajar pada pokok bahasan meneladani ketaatan malaikat-malaikat Allah Swt. Desain eksperimen yang digunakan adalah one-group pretest-posttest design, dimana pada paradigma ini terdapat pre-test sebelum diberi perlakuan.

Desain ini digunakan untuk mengetahui pengaruh model pembelajaran kooperatif tipe student team achievement division terhadap hasil belajar pokok bahasan meneladani ketaatan malaikat-malaikat Allah Swt kelas VII SMP Negeri 3 Padangsidimpuan.Terdapat dua kelas yang digunakan.Satu kelas eksperimen dan satu kelas berperan sebagai kelas kontrol.

Populasi yang diambil dalam penelitian ini adalah seluruh siswa kelas VII SMP Negeri 3 Padangsidimpuan

Tabel 1

Populasi Penelitian

\begin{tabular}{|c|c|c|}
\hline No & KELAS & JUMLAH \\
\hline 1 & VII-1 & 25 Orang \\
\hline 2 & VII-2 & 27 Orang \\
\hline 3 & VII-3 & 28 Orang \\
\hline 4 & VII-4 & 30 Orang \\
\hline 5 & VII-5 & 29 Oarang \\
\hline 6 & VII-6 & 26 Oarang \\
\hline 7 & VII-7 & 24 Orang \\
\hline 8 & VII-8 & 25 Orang \\
\hline 9 & VII-9 & 27 Orang \\
\hline 10 & VII-10 & 29 Orang \\
\hline 11 & VII-11 & 23 Orang \\
\hline & JUMLAH & 293 Orang \\
\hline
\end{tabular}

Teknik pemilihan sampel yang dilakuan peneliti dengan menggunakan cluster sampling. Teknik pemilihan sampel dengan cara cluster sampling digunakan bilamana populasi tidak terdiri dari indivudu-individu, melainkan terdiri dari kelompok-kelompok individu atau

\footnotetext{
${ }^{8}$ Mulyani, “Penggunaan metode eksperimen untuk meningkatkan hasil belajar', Jurnal Pendidikan Profesional, Volume 4, No. 3 Desember 2015, hlm. 46.

${ }^{9}$ Sugiyono, Metode Penelitian Kuantitatif dan Kualitatif (Bandung: Alfabeta, 2013), hlm. 72.
} 
cluster. ${ }^{10}$ Sehingga yang menjadi sampel dalam penelitian ini adalah siswa kelas VII-7 yang terdiri dari 24 orang sebagai kelas kontrol dan VII-8 yang terdiri dari 24 orang sebagai kelas eksperimen. Dengan demikian jumlah sampel pada penelitian ini yaitu 48 orang.

Instrumen pengumpulan data yang digunakan dalam peneilitian ini adalah tes.Tes yang akan digunakan peneliti adalah tes pilihan ganda. Tes ini diberikan kepada kedua kelompok sampel dengan tes yang sama. Soal untuk penelitian ini sebanyak 20 soal.

\section{Hasil dan Pembahasan}

1. Hasil Penelitian

Data tersebut diperoleh dari 48 peserta didik, dimana kelas VII-8 sebagai kelas eksperimen sebanyak 24 orang peserta didik, dan kelas VII-7 sebagai kelas kontrol sebanyak 24 peserta didik. Dimana kelas eksperimen proses pembelajaran dilakukan dengan dengan menggunakan kooperatif tipe Student Team Achievement Division dan pada kelas kontrol proses pembelajaran menggunakan metode ceramah, diskusi dan Tanya jawab. Adapun deskripsi hasil penelitian yaitu:

a. Hasil Data Pretest Kelas Eksperimen dan Pretest Kelas Kontrol

Dalam proses pembelajaran yang menggunakan kooperatif STAD dimulai dengan pemberian pretes, kemudian peserta didik dibagi kedalam kelompok belajar secara heterogen dan setiap kelompok memastikan anggotanya telah memahami atau menguasai matri mengenai meneladani ketaatan malaikat-Malaikat Allah.

Data di deskripsikan untuk memperoleh gambar tentang karakteristik variabel penelitian. Deskripsi data menyajikan nilai tertinggi, nilai terendah, mean, modus, median, standar deviasi, variansi dan rentang data.

Tabel 2

Data Hasil Belajar PAI (Pretes) Kelas Eksperimen (VII-8)

\begin{tabular}{|l|c|}
\hline \multicolumn{1}{|c|}{ Distribusi } & Nilai \\
\hline Nilai Maksimal & 75 \\
\hline Nilai Menimal & 40 \\
\hline Rentangan & 35 \\
\hline Banyak Kelas & 6 \\
\hline Panjang Kelas & 6 \\
\hline Mean & 61.5 \\
\hline Standar Deviasi & 9.27 \\
\hline
\end{tabular}

${ }^{10}$ S. Margono,Metodologi Penelitian Pendidikan (Jakarta: Rineka Cipta, 2010), hlm. 125. 


\begin{tabular}{|l|c|} 
Jumlah Sampel & 24 \\
\hline Modus & 68,5 \\
\hline Median & 74,5 \\
\hline \multicolumn{1}{|c|}{ Exi } & 1480 \\
\hline
\end{tabular}

Grafik 1

Skema Gelombang Tingkat Hasil Pre-Test Kelas Eksperimen

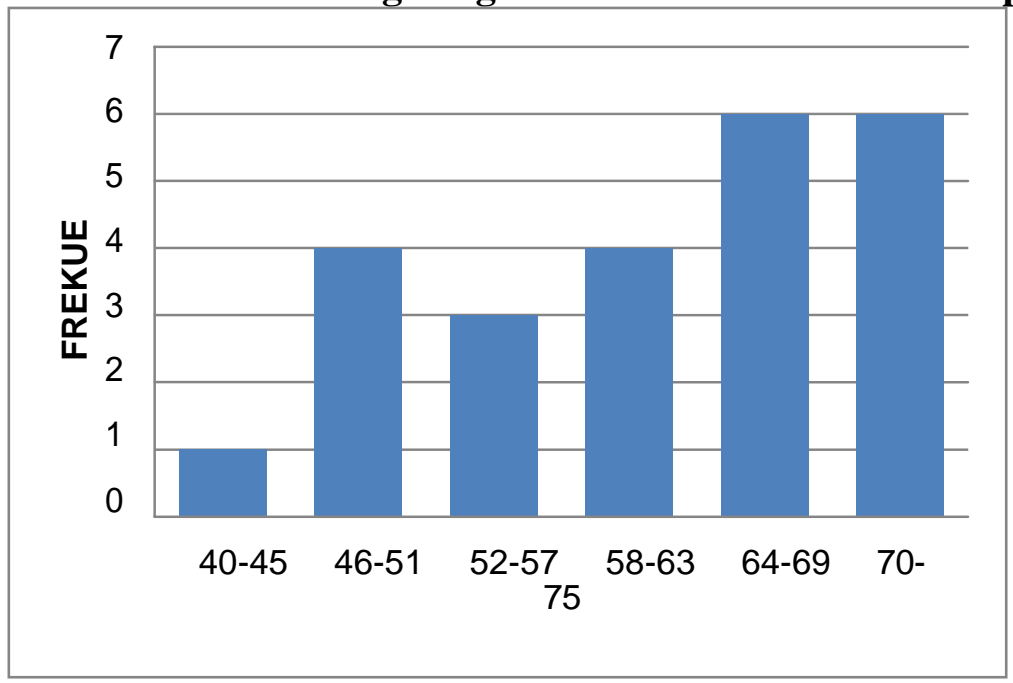

Data di deskripsikan untuk memperoleh gambar tentang karakteristik variabel penelitian. Deskripsi data menyajikan nilai tertinggi, nilai terendah, mean, standar deviasi, variansi dan rentang data, median, modus.

Tabel 3

Data Hasil Belajar PAI (Pretes) Kelas Kontrol (VII-7)

\begin{tabular}{|l|c|}
\hline \multicolumn{1}{|c|}{ Distribusi } & Nilai \\
\hline Nilai Maksimal & 80 \\
\hline Nilai Menimal & 35 \\
\hline Rentangan & 45 \\
\hline Banyak Kelas & 6 \\
\hline Panjang Kelas & 8 \\
\hline Mean & 64.38 \\
\hline Standar Deviasi & 11.9 \\
\hline Jumlah Sampel & 24 \\
\hline Median & 69,5 \\
\hline Modus & 65,5 \\
\hline$\sum X i$ & 1505 \\
\hline
\end{tabular}


Tingkat keberhasilan siswa yang didapatkan oleh para peserta didik ini dapat dilihat pada kolom dibawah ini:

\section{Grafik 2}

\section{Skema Gelombang Hasil Pre-test Pada Kelas Kontrol}

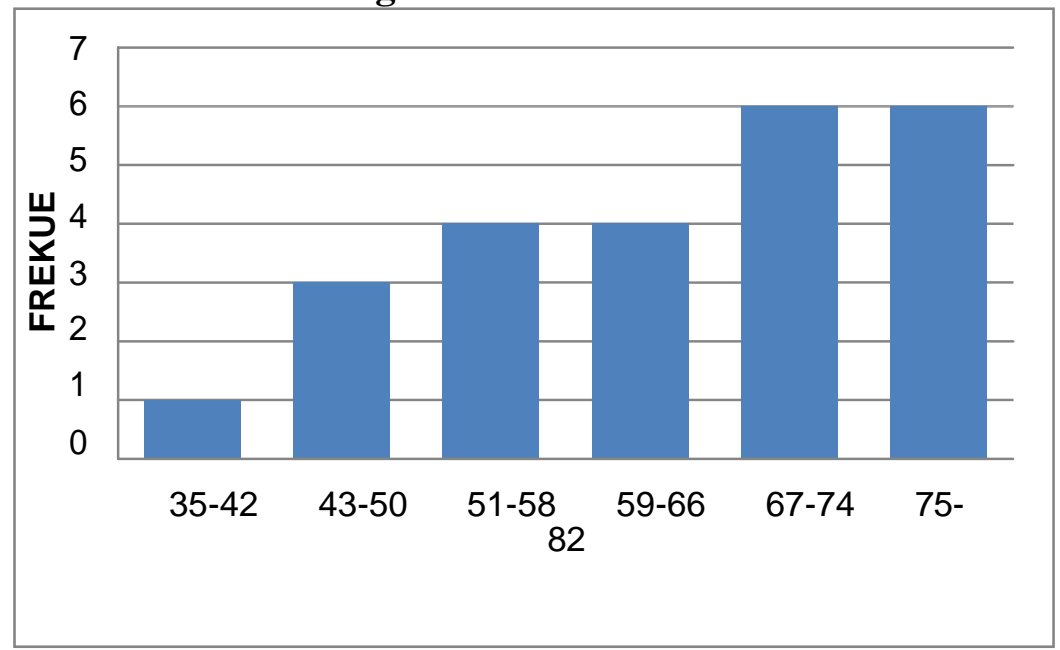

b. Hasil Post-test Eksperimen (Student Tiam Achievement Division) dan Pots-test Kelas Kontrol.

Hasil nilai post-tes kelas eksperimen dengan model Student Tiam Achievement Division dan Pots-test Kelas Kontrol. Data dideskripsikan untuk memperoleh gambar tentang karakteristik variabel penelitian. Deskripsi data menyajikan nilai tertinggi, nilai terendah, mean, standar deviasi, dan rentang data, median, modus.

Tabel 4

Persentasi Nilai (Post test) Kelompok Eksperimen (VII-8)

\begin{tabular}{|l|c|}
\hline \multicolumn{1}{|c|}{ Distribusi } & Nilai \\
\hline Nilai Maksimal & 95 \\
\hline Nilai Menimal & 70 \\
\hline Rentangan & 25 \\
\hline Banyak Kelas & 6 \\
\hline Panjang Kelas & 5 \\
\hline Mean & 83.46 \\
\hline Standar Deviasi & 7.51 \\
\hline Jumlah Sampel & 24 \\
\hline Median & 83,5 \\
\hline Modus & 80,5 \\
\hline$\sum X i$ & 1960 \\
\hline
\end{tabular}


Hasil dari proses pemebelajaran siswa dapat dilihat melalui histogram ini:

Grafik 3

\section{Histogram Nilai Post-test Pada Kelas Eksperimen}

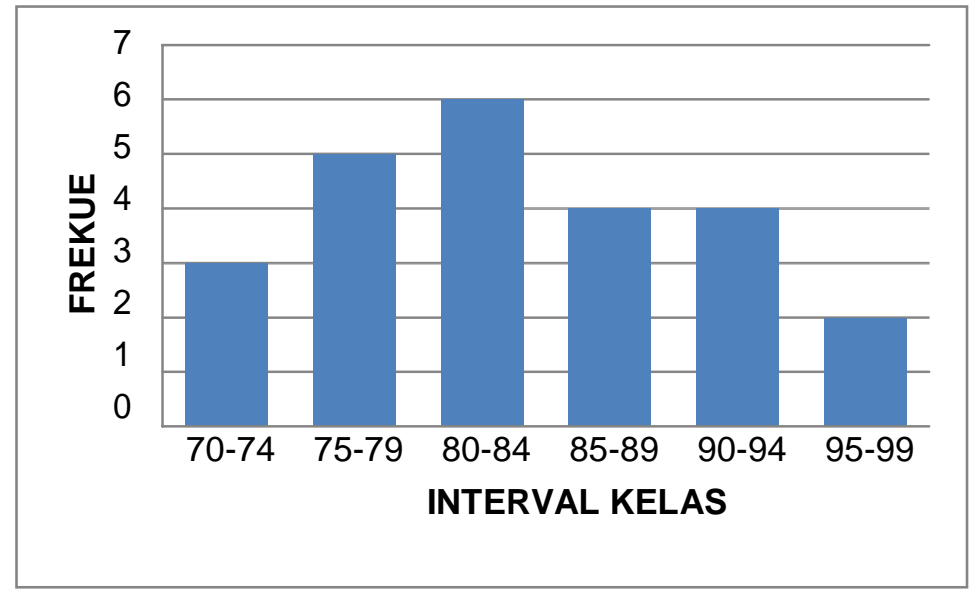

Tabel 5

Data Hasil Belajar PAI (Post test) Kelas Kontrol (VII-7)

\begin{tabular}{|l|c|}
\hline \multicolumn{1}{|c|}{ Distribusi } & Nilai \\
\hline Nilai Maksimal & 75 \\
\hline Nilai Menimal & 40 \\
\hline Rentangan & 35 \\
\hline Banyak Kelas & 6 \\
\hline Panjang Kelas & 8 \\
\hline Mean & 68.8 \\
\hline Standar Deviasi & 9.23 \\
\hline Jumlah Sampel & 24 \\
\hline Median & 67,7 \\
\hline Modus & 66,9 \\
\hline$\sum X i$ & 1660 \\
\hline
\end{tabular}

Perolehan siswa dari uji post-test yang telah dilakukan sebelumnya di kelas eksperiment dapat dibuktikan dengan merujuk pada keterangan di bawah ini:

\section{Grafik 4}

\section{Histogram Perolehan Post-test Pada Kelas Kontrol}




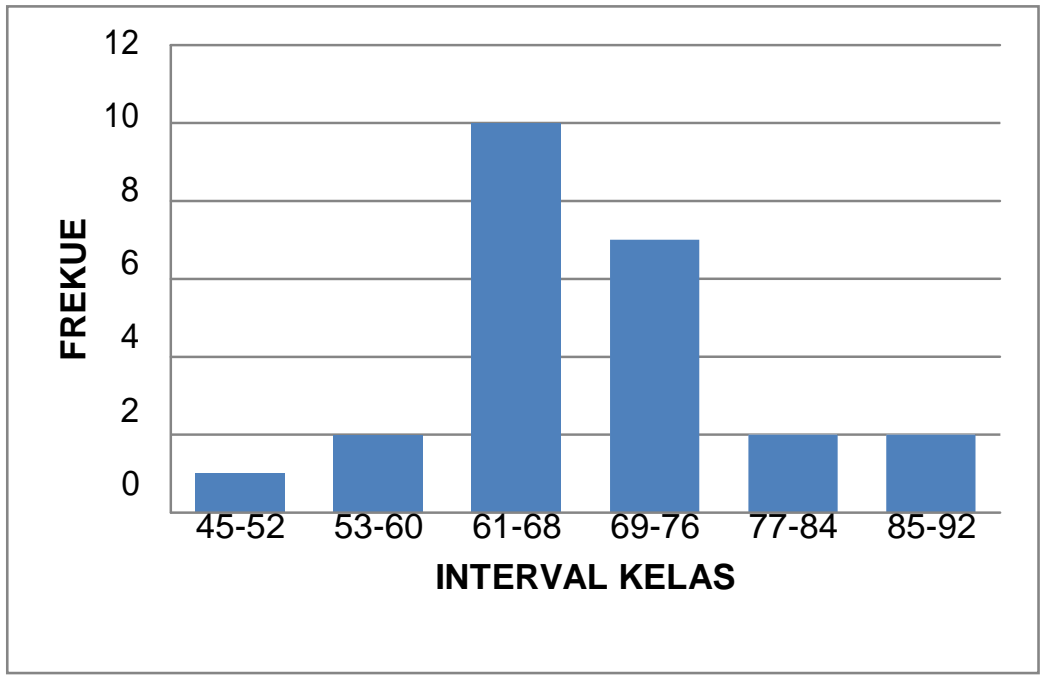

Data postest menunjukkan bahwa kedua kelas eksperimen menunjukkan bahwa kedua kelas eksperimen dan konrol memperoleh nilai rata-rata nilai yang berbeda. Perbedaan nilai yang diperoleh kedua kelas dapat dilihat melalui histogram berikut.

Gambar 1

Histogram Nilai Hasil Belajar Siswa Kelas Eksperimen $\left(\mathrm{VII}^{8}\right)$ dan Kontrol (VII

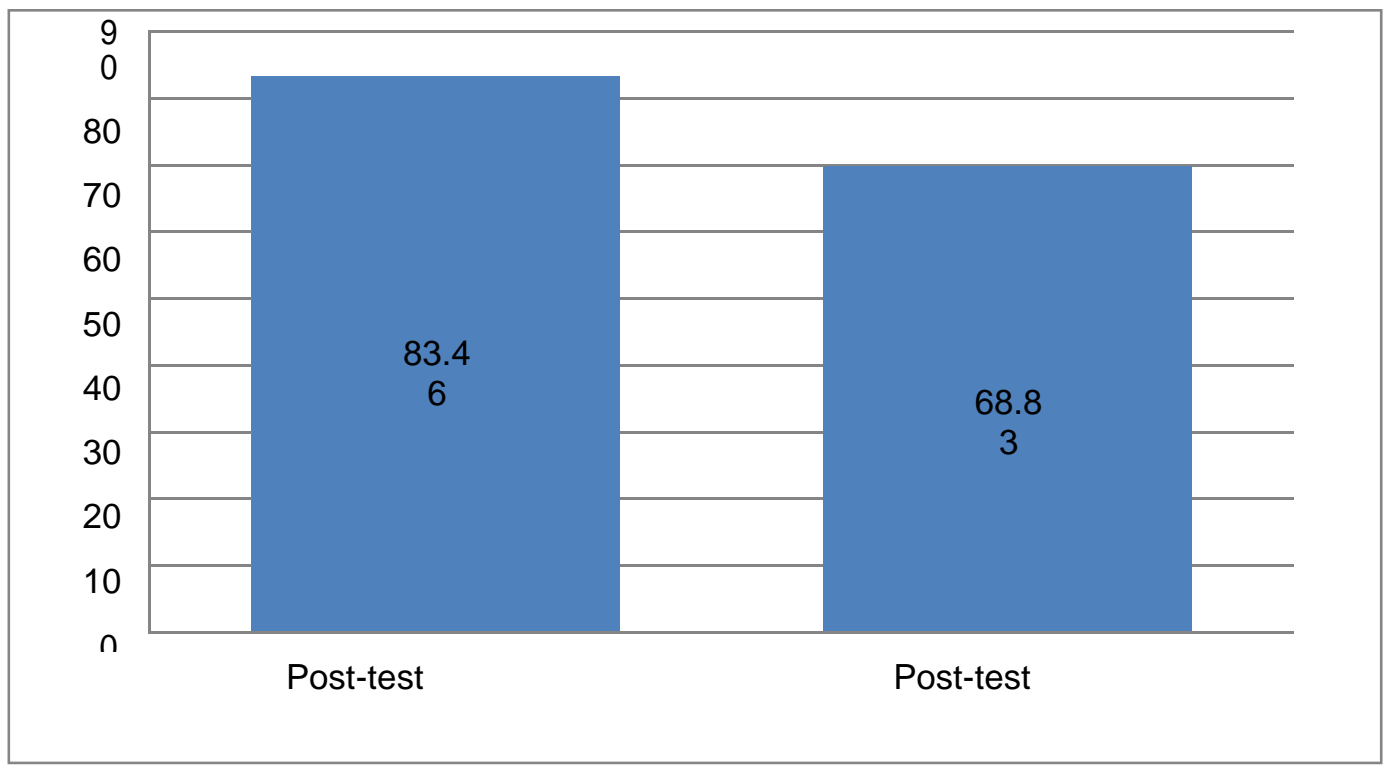

a. Uji Normalitas 
Agar mendapatkan data yang baik, maka dalam penelitian ini akan menggunakan Uji coba normalitas, hal ini dilakukan guna menghitung tingkat normalnya suatu data di dalam penelitian. Dianggap normal berbunyi $X_{\text {hitung }}<X_{\text {tabel. }}$. Dalam hal ini, penaliti akan menguji tingkat kenormalitasan menggunakan rumus Chi-kuadrat. Perolehan hasilnya dapat dilihat sebagai berilut:

\section{Tabel 6}

Hasil Uji Normalitas Pre-test Kelompok Kontrol dan Eksperimen

\begin{tabular}{|c|c|c|c|c|c|}
\hline Variabel & $\begin{array}{c}\text { Banyak } \\
\text { Sampel }\end{array}$ & $\begin{array}{c}\text { Taraf } \\
\text { Signifikan }\end{array}$ & $\mathrm{X}_{\text {hitung }}$ & $\mathrm{X}_{\text {tabel }}$ & Keterangan \\
\hline $\begin{array}{c}\text { Pre-test } \\
\text { Eksperimen }\end{array}$ & 24 & 0.05 & 6.90 & 7.815 & Normal \\
\hline $\begin{array}{c}\text { Pre-test } \\
\text { Kontrol }\end{array}$ & 24 & 0.05 & 3.53 & 7.815 & Normal \\
\hline
\end{tabular}

Suatu data diatakan berdistribusi normal jika $\mathrm{X}_{\text {hitung }}^{2}<\mathrm{X}_{\text {tabel }}^{2}$ dengan $\mathrm{dk}=\mathrm{k}-3$ dan tarafsignifikan 5\%. Dari data di atas dapat dilihat bahwa $\mathrm{X}_{\text {tabel }}^{2}$ kedua kelas kontrol dan eksperimen lebih kecil dari $\mathrm{X}_{\text {tabel }}$ dengan dk untuk kelas kontrol $=\mathrm{k}-3$

$=6-3$ dan untuk kelas eksperimen $\mathrm{dk}=6-3=3$, sehingga dapat disimpulkan bahwa kedua kelas berdistribusi normal.

b. Uji Homogenitas Varians

Uji homogenitas dilakukan untuk mengetahui apakah data nilai awal sampel mempunyai varians yang homogeny (sama). Dibawah ini adalah hasil perhitungan uji homogenitas dengan nilai tabelnya.

\section{Tabel 7}

Hasil Uji Homogenitas Varians

\begin{tabular}{|c|c|c|c|c|c|}
\hline \multicolumn{2}{|c|}{$\begin{array}{c}\text { Varians } \\
\text { Eksperimen dan Kontrol }\end{array}$} & $\begin{array}{c}\text { Taraf } \\
\text { Signifikan }\end{array}$ & $F_{\text {hitung }}$ & F $_{\text {tabel }}$ & Ket \\
\hline 94.928 & 145.61 & 0.05 & 1.53 & 2.77 & Homogen \\
\hline
\end{tabular}

$F_{\text {hitung }}$ diperoleh dengan menggunakan varians terbesar dengan varians terkecil.Varians terbesar data adalah 145.61 dan varians terkecil 94.928.data dikatakan homogeny apabila $F_{\text {hitung }}<F_{\text {tabel }}$ sehingga diperoleh $1.53<2.77$ artinya kedua kelas eksperimen dan kontrol mempunyai varians yang sama.

c. Uji Perbedaan Dua Rata-rata 
Analisis yang digunakan adalah uji-t untuk melihat apakah kedua kelas control dan eksperimen tidak mempunyai perbedaan rata-rata dapat dilihat pada tabel berikut ini:

\section{Tabel 8}

Hasil Uji Perbedaan Dua Rata-Rata

\begin{tabular}{|c|c|c|}
\hline Distribusi & $\mathrm{t}_{\text {hitung }}$ & $\mathrm{t}_{\text {tabel }}$ \\
\hline Perbedaan dua rata-rata & $-0,90$ & 1,677 \\
\hline
\end{tabular}

Dari data di atas dapat disimpulkan bahwa $\mathrm{t}_{\text {hitung }}-0,90<\mathrm{t}_{\text {tabel }} 1.677$ yang berarti kedua sampel tidak memiliki perbedaan rata-rata yang signifikan.

Tabel 9

Hasil Uji Normalitas Post-test Kelas Kontrol dan Eksperimen

\begin{tabular}{|c|c|c|c|c|c|}
\hline Variabel & $\begin{array}{c}\text { Jumlah } \\
\text { Sampel }\end{array}$ & $\begin{array}{c}\text { Taraf } \\
\text { Signifikan }\end{array}$ & $\mathrm{X}_{\text {hitung }}$ & $\mathrm{X}_{\text {tabel }}$ & Keterangan \\
\hline $\begin{array}{c}\text { Post-Test } \\
\text { Eksperimen }\end{array}$ & 24 & 0.05 & 3.37 & 7.815 & Normal \\
\hline $\begin{array}{c}\text { Post-Test } \\
\text { Kontrol }\end{array}$ & 24 & 0.05 & 7.28 & 7.815 & Normal \\
\hline
\end{tabular}

Suatu data dikatakan berdistribusi normal jika $X_{\text {hitung }}<X_{\text {tabel }}$ dengan dk $=k-$ 3 dan taraf signifikan 5\% . dari data di atas dapat dilihat bahwa $X_{\text {hitung kedua kelas }}$ eksperimen dan kontrol lebih kecil dari $\mathrm{X}_{\text {tabel }}$ dengan $\mathrm{dk}$ untuk kelas eksperimen $=\mathrm{k}$ $3=6-3=3$, dan kelas kontrol $\mathrm{dk}=\mathrm{k}-3=6-3=3$, sehingga dapat disimpulkan bahwa kedua kelas eksperimen berdistribusi normal.

Tabel 10

Uji Homogenitas Post-tes

\begin{tabular}{|c|c|c|c|c|c|}
\hline \multicolumn{2}{|c|}{ Varians } & $\begin{array}{c}\text { Taraf } \\
\text { Signifikansi }\end{array}$ & $F_{\text {hitung }}$ & $F_{\text {tabel }}$ & Ket \\
\hline Eksperimen & Kontrol & & & & \\
\hline 60.14 & 99.3 & 0.05 & 1.65 & 2.77 & Homogen \\
\hline
\end{tabular}

$F_{\text {hitung }}$ diperoleh dengan menggunakan varians terbesar dengan varians terkecil.Varians terbesar data adalah 99.3 dan varians terkecil 60.14.data dikatakan homogen apabila $F_{\text {hitung }}<F_{\text {tabel }}$ sehingga diperoleh $1.65<2.77$ artinya kedua kelas eksperimen dan control mempunyai varians yang sama. 
Setelah diberikan perlakuan terhadap kedua kelas kontrol dan eksperimen bahwa kedua kelas masih berdistribusi normal. Maka dapat dilanjutkan dengan uji -t.

$\mathrm{H}_{\mathrm{O}}=\mu_{1}<\mu_{2}$, artinya rata-rata hasil belajar siswa pada pokok bahasan meneladani

ketaatan malaikat-malaikat Allah Swt. tidak lebih baik dari rata-rata hasil belajar siswa tanpa menggunakan model Student Team Achievement Division.

$\mathrm{Ha}=\mu_{1}>\mu_{2}$, artinya ada pengaruh yang signifikan terhadap hasil belajar Pendidikan Agama Islam pokok bahasan meneladani ketaatan malaikat-malaikat Allah Swt. kelas VII di SMP Negeri 3 Padangsidimpuan dengan menggunkan model Student Team Achivement Divisen (STAD).

\section{Tabel 11}

Hasil Uji Hipotesis Kelas Eksperimen dan Kontrol

\begin{tabular}{|l|c|l|l|l|l|}
\hline Kelompol & $\mathrm{N}$ & Mean & & $\mathrm{t}_{\text {hitung }}$ & $\mathrm{t}_{\text {tabel }}$ \\
\hline Eksperimen & 24 & 83.46 & 60.14 & \multirow{2}{*}{5.66} & \multirow{2}{*}{1.677} \\
\cline { 1 - 5 } Kontrol & 24 & 68.8 & 99.3 & & \\
\hline
\end{tabular}

Berdasarkan pengujian nilai rata-rata hasil belajar Pendidikan Agama Islam pokok bahasan meneladani ketaatan Malaikat-Malaikat Allah SWT. diperoleh harga $t_{\text {hitung }}=5.66$ dengan taraf signifikan $\mathrm{a}=0,05$ dan derajat kebebasan $(\mathrm{dk}=\mathrm{n}-2)=22$ diperioleh nilai $\mathrm{t}_{\text {tabel }}=$ 1.677 (perhitungan dapat dilihat pada lampiran 18). Data yang terlihat bahwa $t_{\text {hitung }}$ berada diantara $t_{\text {tabel }}$ artinya $t_{\text {hitung }}>t_{\text {tabel }}$ yaitu $5.66>1.677$ yang menunjukkan $\mathrm{H}_{\mathrm{a}}$ diterima dan $\mathrm{H}_{0}$ ditolak. Sehingga dapat disimpulkan bahwa terdapat pengaruh model pembelajaran kooperatif tipe Student Team Achivemant Division terhadap hasil belajar pokok bahasan meneladani ketaatan malaikat-malaikat Allah Swt. kelas VII di SMP Negeri 3 Padangsidimpuan.

2. Pembahasan Hasil Penelitian

Dalam model pembelajaran Student Team Achievement Divisionsiswa dibagi menjadi beberapa kelompok, di setiap kelompok diwajibkan untuk saling berinteraksi dengan teman kelompoknya dan saling memahamkan anggotanya mengenai materi tentang meneladani ketaatan malaikat-malaikat Allah. Dalam model pembelajaran ini setiap kelompok mempresentasikan hasil diskusi mereka sehingga terjadi komunikasi antara 
anggota kelompok dan kelompok lainnya. Sedangkan untuk kelas kontrol hasil diberikan metode ceramah, diskusi dan Tanya jawab.

Kedua kelas eksperimen dan kontrol berangkat dari kondisi awal yang sama, yang mana nilai rata-rata kelas eksperimen sebelum diberi perlakuan yaitu 61.5 sedangkan nilai rata-rata kelas kontrol yaitu 64.38. Setelah dilakukan model pembelajaran Student Team Achievement Division di kelas eksperimen yaitu kelas VII-8 nilai rata-tara hasil belajar PAI siswa meningkat menjadi 83.46.Sedangkan kelas kontrol nilai rata-ratanya hanya 7.43.Hal ini menunjukkan bahwa model pembelajaran Student Team Achievement Division dapat memberikan pengaruh yang positif terhadap hasil belajar PAI siswa.

Berdasarkan pengujian hipotesis yang dilakukan sebelumnya diperoleh bahwa $\mathrm{H}_{\mathrm{o}}$ ditolak. dengan demikian hipotesis alternatif $\left(\mathrm{H}_{\mathrm{a}}\right)$ menyatakan hasil belajar Pendidikan Agama Islam siswa yang diajarkan dengan menggunakan model pembelajaran aktif Student Team Achievement Division memiliki perubahan nilai dibandingkan dengan pembelajaran yang selama pembelajaran menerapkan metode Tanya jawab, diskusi serta ceramah.

Maknanya sebelum menguji STAD kegiatan proses belajar mengajar masih terfokus kepada guru, akibatnya siswa tidak menghadirkan dirinya selama jam pelajaran berlanjut. Tetapi setelah model pembelajaran STADditerapkan di ruang kelas eksperimen proses pembelajaran semakin akif dan kreatif dibanding penggunaan model sebelunya yaitu kelas kontrol dengan metode ceramah, diskusi dan Tanya jawab dalam materi tentang meneladani ketaatan Malaikat-Malaika Allah SWT.

\section{Kesimpulan}

Berdasarkan hasil penelitian dapat disimpulkan bahwa terdapat pengaruh metode Studet Team Achievemen Division terhadap hasil belajar siswa pokok bahasan meneladani ketaatan Malaikat-malaikat Allah Swt kelas VII di SMP Negeri 3 Padangsidimpuan. Hal ini menunjukkan, perolehan post-test kelas eksperimen yang mengaplikasikan model Studet Team Achievemen Division (rata-rata 83.46), nenunjukkan nilai yang lebih tinggi dibandingkan dengan kelas kontrol yang menggunakan metode 
ceramah, diskusi dan Tanya jawab (rata-rata 7.43). Sedangkan hasil uji-t diperoleh thitung $5.66>t_{\text {tabel }} 1.677$ dengan masing-masing sampel 24 siswa kelas eksperimen dan 24 kelas kontrol.

\section{DAFTAR PUSTAKA}

Asri Budi ningsih, Belajar dan Pembelajaran, Jakarta: PT. Rineka Cipta, 2005.

Haidar Putra Daulay, Pendidikan Islam Di Indonesia, Medan: Perdana Publishing, 2012.

Hamruni, Strategi Pembelajaran, Yogyakarta: Insan Media, 2012.

Mulyani, "Penggunaan Metode Eksperimen untuk Meningkatkan Hasil Belajar", Jurnal Pendidikan Profesional, Volume 4, No. 3 Desember 2015.

Sugiyono, Metode Penelitian Kuantitatif dan Kualitatif, Bandung: Alfabeta, 2013.

Supriyadi, Syamsul Bahri, Amiruddin Kade, "Pengaruh Mode Pembelajaran Kooperatif Tipe STAD Dalam Meningkatkan Hasil Belajar Fisika Peserta Didik Kelas X SMK N 6 Palu Tahun Ahjaran 2016/2019," Jurnal Magistra, Volume 5, no. 2 Juli 2018.

Syaiful Bahri Djamarah dan Aswan Zain, Strategi Belajar Mengajar,Jakarta: PT. Rineka Cipta, 2006.

S. Margono, Metodologi Penelitian Pendidikan, Jakarta: Rineka Cipta, 2010 